\title{
Risk Factors for the Morbidity and Mortality of Stoma Closure
}

\author{
Gizem Kilinc, Mehmet Ustun, Korhan Tuncer and Ismail Sert \\ Department of General Surgery, Izmir University of Health Sciences, Tepecik Training and Research Hospital, Izmir, Turkey
}

\begin{abstract}
Objective: To identify the risk factors for postoperative complications of stoma closures.

Study Design: Descriptive study.

Place and Duration of Study: Department of General Surgery, Izmir University of Health Sciences, Tepecik Training and Research Hospital, Izmir Turkey from October 2008 to December 2018.

Methodology: A total of 179 patients were divided into two groups according to presence or absence of postoperative complications. Differences between these two groups were analysed with tests of proportion; $p<0.05$ value was considered statistically significant. The results are reported as odds ratios (ORs) with $95 \%$ confidence interval $(\mathrm{Cl})$.

Results: The median age of the patients with postoperative complications was 57.00 (40.00-67.00) and 30/55 (54.5\%) of them were males. American Society of Anesthesiology (ASA) score and coronary artery disease had significant association with postoperative complications of stoma closure $(p=0.033, p=0.024)$. Although colostomy was not associated with presence of postoperative complications, but when the authors analysed correlations of colostomy with postoperative complications separately, it was found that colostomy was a risk factor for postoperative ileus (OR $0.257,95 \% \mathrm{Cl} 0.081-0.821 ; p=0.026$ ).

Conclusion: ASA score and coronary artery disease should be considered as risk factors for complications of stoma closure. Colostomy should be considered as a risk factor for postoperative ileus.
\end{abstract}

Key Words: Colostomy, lleostomy, Stoma closure, Risk factors.

How to cite this article: Kilinc G, Ustun M, Tuncer K, Sert I. Risk Factors for the Morbidity and Mortality of Stoma Closure. J Coll Physicians Surg Pak 2021; 31(09):1085-1088.

\section{INTRODUCTION}

Ostomy is mainly used for intestinal and colonic diversion as a treatment option for various diseases. It is usually performed in the emergency surgeries when primary anastomosis is unfeasible, especially in haemodynamically unstable patients, due to sepsis or multiorgan dysfunction. ${ }^{1}$ It can be also used in patients with fecal peritonitis for preventing the anastomotic leakage. On the other hand, stoma can be used in elective surgery, such as ileostomies applied to reduce anastomotic leakage after resection in rectal cancer. ${ }^{2}$ Procedure of stoma closure can be very difficult for the surgeon, depending on the patient's previous operations and comorbidities. ${ }^{3}$ Stomas are usually temporary but up to $74 \%$ of the cases can become permanent according to the patient's age, comorbidities and rectal stump size. .,5 $^{4 .}$

Correspondence to: Dr. Gizem Kilinc, Department of General Surgery, Izmir University of Health Sciences, Tepecik Training and Research Hospital, Izmir, Turkey E-mail: drgizemkilinc@gmail.com

Received: November 19, 2020; Revised: January 28, 2021; Accepted: February 25, 2021

DOI: https://doi.org/10.29271/jcpsp.2021.09.1085
In previous studies, stoma closure complications are reported up to $55 \%$ and mortality up to $4 \%$. Therefore, patient should be examined carefully before the operation. ${ }^{1}$

In the present study, the aim was to identify the risk factors for morbidity and mortality in stoma closures.

\section{METHODOLOGY}

Patients, who underwent stoma closure at Izmir University of Health Sciences, Tepecik Training and Research Hospital, Izmir Turkey between October 2008 and December 2018, were retrospectively analysed. Patients younger than 18 years, with incomplete medical records and those who had more than two previous abdominal operations, were excluded. Parameters affecting the complications of stoma closure were determined as age, gender, patients' comorbidities, preoperative American Society of Anesthesiology (ASA) score, stoma type, preoperative levels of hemoglobin and albumin, interval between stoma opening and closure, previous diagnosis for operation and anastomosis technique. Patients' comorbidities were categorised as hypertension, diabetes mellitus, coronary artery disease, atrial fibrillation, congestive heart failure and chronic obstructive pulmonary disease. Type of stoma was classified as ileostomy and colostomy by specifying the end and loop features. Two main closure techniques were used for stoma closure. All stoma closures were performed under general anesthesia. All patients 
took prophylactic parenteral antibiotic treatment with cefazolin one hour prior to operation. Loop stomas were closed with a circumferential peristomal incision. The incision was deepened down to the fascia and after mobilisation of all bowel quadrants, anastomosis was done with handsewn or stapled techniques. The anastomosed bowel segment was returned to abdominal cavity and the fascial defect was closed with continuous or interrupted sutures. End stomas were closed by open surgery. After midline incision, end stoma was taken into the abdominal cavity after mobilisation from the abdominal wall. Anastomosis was performed with handsewn or stapled techniques after preparing the proximal and distal parts of the bowel segments. At the end, fascial defects were closed either with continuous or interrupted sutures.

Postoperative complications were categorised as anastomotic leakage, surgical site infection, bowel obstruction, evisceration, enterocutaneous fistula and gastrointestinal bleeding. After data collection, patients were divided into two groups as patients with postoperative complications and patients without postoperative complications. Patients having any of the postoperative complications mentioned above, were included in the group of patients with postoperative complications.

Difference between these two groups for the parameters affecting stoma closure complications were statistically analysed with IBM SPSS statistics software, version 25.0. As the descriptive statistics, the number of units $(n)$, percent $(\%)$, median (Q1-Q3) values were given. Pearson Chi-Square and Ficher's Exact test were used to evaluate categorical variables. The results are reported as odds ratios (ORs) with 95\% confidence interval $(\mathrm{Cl})$. The normal distribution of data's continuous variables was evaluated by Kolmogrov-Smirnov normality test and Q-Q graphs. In comparison of the continuous variables of the two groups, the Mann-Whitney U-test for variables that did not fit the normal distribution. A $p<0.05$ value was considered statistically significant. Moreover, median length of hospital stay, reoperation rates, and mortality rates were analysed.

\section{RESULTS}

A total of 183 patients underwent stoma closure; among them, 179 patients were found eligible for study as per the inclusion criteria. The median age was 55 (41.00-65.00) years and 112 $(62.6 \%)$ of the patients were males. The median age of the patients with postoperative complications was found 57 (40.00-67.00), and 30 (54.5\%) of them were males. Both, age and the gender, were not found as a risk factor for postoperative complications of stoma closure $(p=0.834$, and $p=0.140)$. Diagnosis of the all patients before the stoma creation operation are presented in Tablel.

Majority, i.e. $78.2 \%$ of the operations were emergency surgery in patients with postoperative complications and type of the surgery was notfound associated with the postoperative complications (OR 0.837, 95\% Cl 0.392-1.787; $p=0.646$ ). Again, majority i.e. $74.5 \%$ of stomas were colostomy and $67.3 \%$ of them were found to be end stoma. The type of the stoma was not associated with postoperative complications of stoma closure in patients with postoperative complications (Colostomy group; OR 0.632, 95\% Cl 0.295-1.353; $p=0.235$ and end stoma group; OR $0.908,95 \% \mathrm{Cl} 0.460-1.794 ; p=0.782)$. The median time for hospital stay after stoma closure in patients with postoperative complications was 11 (9-16) days and found to be associated with postoperative complications $(p<0.001)$. Increased preoperative ASA score was found to be associated with postoperative complications of stoma closure $(p=0.033)$.

Table I: Patients' diagnosis for the operation of stoma creation.

\begin{tabular}{|l|c|c|}
\hline Diagnosis & $\begin{array}{c}\text { Number of } \\
\text { patients } \\
(\mathbf{n})\end{array}$ & $\begin{array}{c}\text { Percentage } \\
(\mathbf{\%})\end{array}$ \\
\hline Colon cancer & 58 & 32.4 \\
\hline Rectum cancer & 9 & 5 \\
\hline Mesenteric vascular disease & 5 & 2.8 \\
\hline Colonic diverticular perforation & 28 & 15.6 \\
\hline Stab wound & 9 & 5 \\
\hline Perforation due to rectal foreign bodies & 16 & 8.9 \\
\hline Sigmoid volvulus & 15 & 8.4 \\
\hline Ovarian cancer & 13 & 7.3 \\
\hline Fournier's gangrene & 12 & 6.7 \\
\hline Gunshot wound & 4 & 2.2 \\
\hline Blunt abdominal trauma & 5 & 2.8 \\
\hline İnflammatory bowel diseases & 5 & 2.8 \\
\hline
\end{tabular}

Among the comorbidities of the patients, only coronary artery disease was significantly associated with the presence of a postoperative complication (OR 4.051, 95\% Cl 1.261-13.01; $p=0.024)$. The median preoperative level of hemoglobin was $13.0 \mathrm{~g} / \mathrm{dl}$ (11.90-14.30) in patients with postoperative complications and it was not a risk factor for any of the postoperative complications $(p=0.668)$. The median time between first operation and stoma closure was 6 months (IQR 4-9) in patients with postoperative complications and was not associated with postoperative complications either $(p=0.093)$. Although colostomy was not associated with presence of postoperative complications when the authors analysed correlations of colostomy with postoperative complications separately, it was found that colostomy as a risk factor for postoperative ileus (OR $0.257,95 \% \mathrm{Cl}$ $0.081-0.821 ; p=0.026)$. All parameters that evaluated for the postoperative complications of stoma closures are presented in Table II and Table III with their $p$ values and odds ratios in detail.

\section{DISCUSSION}

Stomas are employed for diverting the colonic or intestinal fluid in patients, who have a risk for anastomotic leakage. In hemodynamically unstable and septic patients, stomas can be the most important part of the surgery for patients' survival in emergency surgeries. ${ }^{1,6}$ Until today, there has been no evidencebased data that diverting stoma influences survival after elective rectal cancersurgery. ${ }^{7,8}$

Although the closure of stoma might seem as a rather simple operation, different studies have shown a varying frequency and pattern of complications which could even cause death. ${ }^{9,10}$ 


\begin{tabular}{|c|c|c|c|c|}
\hline & $\begin{array}{l}\text { Patients without } \\
\text { complications } \\
(n=124)\end{array}$ & $\begin{array}{l}\text { Patients with } \\
\text { complications } \\
(n=55)\end{array}$ & p-value & $\begin{array}{l}\text { Odds ratio } \\
(95 \% \mathrm{Cl})\end{array}$ \\
\hline Age; median (Q1-Q3) & $54.5(41.25-65)$ & $57(40-67)$ & 0.834 & \\
\hline $\begin{array}{l}\text { Gender } \\
\text { Male } \\
\text { Female }\end{array}$ & $\begin{array}{l}82(66.1 \%) \\
42(33.9 \%)\end{array}$ & $\begin{array}{l}30(54.5 \%) \\
25(45.5 \%)\end{array}$ & 0.140 & $1.627 \quad(0.851-3.111)$ \\
\hline $\begin{array}{l}\text { ASA score } \\
\text { ASA I } \\
\text { ASA II } \\
\text { ASA III }\end{array}$ & $\begin{array}{l}44(35.5 \%) \\
57(46 \%) \\
23(18.5 \%)\end{array}$ & $\begin{array}{l}9(16.4 \%) \\
34(61.8 \%) \\
12(21.8 \%) \\
\end{array}$ & 0.033 & \\
\hline $\begin{array}{l}\text { Comorbidities } \\
\text { Hypertension } \\
\text { Diabetes mellitus } \\
\text { Coronary artery disease } \\
\text { Atrial fibrillation } \\
\text { Congestive heart failure } \\
\text { Chronic obstructive } \\
\text { pulmonary disease }\end{array}$ & $\begin{array}{l}29(23.4 \%) \\
20(16.1 \%) \\
5(4 \%) \\
1(0.8 \%) \\
2(1.6 \%) \\
20(16.1 \%)\end{array}$ & $\begin{array}{l}11(20 \%) \\
9(16.4 \%) \\
8(14.5 \%) \\
2(3.6 \%) \\
0 \\
13(23.6 \%)\end{array}$ & $\begin{array}{l}0.616 \\
0.969 \\
\mathbf{0 . 0 2 4} \\
0.224 \\
>0.999 \\
0.232\end{array}$ & $\begin{array}{l}0.819(0.375-1.788) \\
1.017(0.431-2.404) \\
4.051(1.261-13.017) \\
4.642(0.412-52.300) \\
1.610(0.734-3.528)\end{array}$ \\
\hline
\end{tabular}

Table III: Parameters and their association with postoperative complications of stoma closure.

\begin{tabular}{|c|c|c|c|c|}
\hline & $\begin{array}{l}\text { Patients without } \\
\text { complications } \\
(n=124)\end{array}$ & $\begin{array}{l}\text { Patients with } \\
\text { complications } \\
(n=55)\end{array}$ & p-value & Odds ratio $(95 \% \mathrm{CI})$ \\
\hline $\begin{array}{l}\text { Preoperative levels of hemoglobin ( } \mathrm{g} / \mathrm{dl} \text { ) } \\
\text { (median) }\end{array}$ & $13.40(11.80-14.40)$ & $13.00(11.90-14.30)$ & 0.668 & \\
\hline $\begin{array}{l}\text { Preoperative levels of albumin (g/dl) } \\
\text { (median) }\end{array}$ & $4.20(4.00-4.50)$ & $4.10(3.80-4.40)$ & 0.090 & \\
\hline $\begin{array}{l}\text { Postoperative hospital stay (median) } \\
\text { (day) }\end{array}$ & $7.00(6.00-9.00)$ & $11.00(9.00-16.00)$ & $<0.001$ & \\
\hline Time to stoma closure (month) & $7.00(5.00-11.00)$ & $6.00(4.00-9.00)$ & 0.093 & \\
\hline $\begin{array}{l}\text { Anastomosis technique } \\
\text { Hand sew } \\
\text { Stapler }\end{array}$ & $\begin{array}{l}68(54.8 \%) \\
56(45.2 \%)\end{array}$ & $\begin{array}{l}26(47.3 \%) \\
29(52.7 \%)\end{array}$ & 0.350 & $1.354(0.717-2.560)$ \\
\hline $\begin{array}{l}\text { Type of first operation } \\
\text { Emergency } \\
\text { Elective }\end{array}$ & $\begin{array}{l}93(75 \%) \\
31(25 \%)\end{array}$ & $\begin{array}{l}43(78.2 \%) \\
12(21.8 \%)\end{array}$ & 0.646 & $0.837(0.392-1.787)$ \\
\hline $\begin{array}{l}\text { Type of stoma } \\
\text { Colostomy } \\
\text { Ileostomy } \\
\text { End } \\
\text { Loop }\end{array}$ & $\begin{array}{l}102(82.3 \%) \\
22(17.7 \%) \\
86(69.4 \%) \\
38(30.6 \%)\end{array}$ & $\begin{array}{l}41(74.5 \%) \\
14(25.5 \%) \\
37(67.3 \%) \\
18(32.7 \%)\end{array}$ & $\begin{array}{l}0.235 \\
0.235 \\
0.782 \\
0.782\end{array}$ & $\begin{array}{l}0.632(0.295-1.353) \\
1.583(0.739-3.391) \\
0.908(0.460-1.794) \\
1.101(0.558-2.174)\end{array}$ \\
\hline
\end{tabular}

In this study, the morbidity rate was found as $30.7 \%$, which can be higher than the rates in some studies; but can be acceptable according to the studies, which reported the morbidity rate as $50 \% .{ }^{11-13}$ On the other hand, the mortality rate as $1.17 \%$, which is similar to the reported literature. Postoperative complications were found as enterocutaneous fistula in $4(2.2 \%)$ patients, gastrointestinal bleeding in 1 $(0.6 \%)$ patient, evisceration in $4(2.2 \%)$ patients, surgical site infection in $37(20.7 \%)$ patients, and anastomotic leakage in 10 (5.6\%) patients.

Risk factors for complications were analysed and increased ASA score was found to be associated with postoperative complications after stoma closure in addition to present literature. ${ }^{12,14}$ Comorbidities also analysed and coronary artery disease was found associated with the postoperative complications, which can also be added new to the literature. As in most studies, low albumin levels were found to be associated with postoperative complications in colorectal surgery and stoma-related complications; but in this study, albumin level was only found as a risk factor for the surgical site infection. ${ }^{15}$ All of the complications were associated with prolonging the hospital stay. From the study of Krebs et al., the interval to stoma closure was not associated with the postoperative complications in patients with postoperative complications. ${ }^{12}$ In the study by Keller et al., stoma type affects the readmission rates but,

in this study, it was not found as associated with the complications. ${ }^{14}$ Schneider et al. reported that anemia is associated with reoperation of ileostomy reversals whereas in this study hemoglobin levels were found not associated with any of the postoperative complications and reoperation rates in patients with postoperative complications $(p=0.668$ and $p=0.784) .{ }^{9}$ Closure of loop ileostomy was reported to have fewer complications than loop colostomy; whereas, correlations of colostomy with postoperative complications separately, found colostomy as a risk factor for postoperative ileus. ${ }^{3,4}$

\section{CONCLUSION}


ASA score and coronary artery disease are risk factors for complications of stoma closure. It was also found that colostomy was a risk factor for postoperative ileus. Therefore, patients with colostomies should be screened carefully before the stoma closure.

\section{ETHICAL APPROVAL:}

This study was approved by the local Eethic Committee of Tepecik Training and Research Hospital.

\section{PATIENTS' CONSENT:}

Informed consents were obtained from the patients to publish the data concerning this study.

\section{CONFLICT OF INTEREST:}

Authors declared no conflict of interest.

\section{AUTHORS' CONTRIBUTION:}

GK: Data analysis, writing and translation of the manuscript.

MU: Design, data analysis and supervision of the manuscript.

$\mathrm{KT}$ : Data analysis and writing of the manuscript.

IS: Writing and supervision of the manuscript.

All authors contributed to the final approval of the manuscript.

\section{REFERENCES}

1. Faure JP, Doucet C, Essique D, Badra Y, Carretier M, Richer $J P$, et al. Comparison of conventional and laparoscopic hartmann's procedure reversal. Surg Laparosc Endosc Percutan Tech 2007; 17(6):495-9. doi: 10.1097/SLE. 0b013e3180 f61762.

2. McArdle CS, McMillan DC, Hole DJ. Impact of anastomotic leakage on long-term survival of patients undergoing curative resection for colorectal surgery. Br J Surg 2005; 92(9):1150-4. doi: 10.1002/bjs.5054.

3. Garber A, Hyman N, Osler T. Complications of Hartmann takedown in a decade of preferred primary anastomosis. Am J Surg 2014; 207(1):60-64. doi: 10.1016/j.amjsurg. 2013.05.006.

4. Daluvoy S, Gonzalez F, Vaziri K, Sabnis A, Brody F. Factors associated with ostomy reversal. Surg Endosc 2008; 22(10):2168-70. doi: 10.1007/s00464-008-0014-X.

5. Toro A, Ardiri A, Mannino M, Politi A, Di Stefano A, Aftab Z, et al. Laparoscopic reversal of hartmann's procedure: State of the art 20 years after the first reported case. Gastroenterol Res Pract 2014; 2014:530140. doi: 10.1155/ 2014/530140.

6. Fonseca AZ, Uramotol E, Santos-Rosa OM, Santın S, Rıbeıro-Jr M. Colostomy closure: Risk factors for complıcations. Arq Bras Cir Dig 2017; 30(4):231-4. doi: 10.1590/0102-6720201700040001.

7. Montedori A, Cirocchi R, Farinella E, Sciannameo F, Abraha I. Covering ileo- or colostomy in anterior resection for rectal carcinoma. Cochrane Database Syst Rev 2010; 5: CD006878. doi: 10.1002/14651858.

8. Gu WL, Wu SW. Meta-analysis of defunctioning stoma in low anterior resection with total mesorectal excision for rectal cancer: Evidence based on thirteen studies. World J Surg Oncol 2015; 13:9. doi: 10.1186/s12957-014-0417-1.

9. Schneider V, Lee LD, Stroux A, Buhr HJ, Ritz JP, Kreis ME, et al. Risk factors for reoperation after ileostomy reversal results from a prospective cohort study. Int J Surg 2016; 36(Pt A):233-9. doi: 10.1016/j.ijsu.2016.10.043

10. El-Hussuna A, Lauritsen M, Bülow S. Relatively high incidence of complications after loop ileostomy reversal. Dan Med J 2012; 59(10):A4517.

11. Chow A, Tilney HS, Paraskeva P, Jeyarajah S, Zacharakis E, Purkayastha $\mathrm{S}$. The morbidity surrounding reversal of defunctioning ileostomies: A systematic review of 48 studies including 6,107 cases. Int J Colorectal Dis 2009; 24(6):711-23. doi: 10.1007/s00384-009-0660-z.

12. Krebs B, Ivanecz A, Potrc S, Horvat M. Factors affecting the morbidity and mortality of diverting stoma closure: Retrospective cohort analysis of twelve-year period. Radiol Oncol 2019; 53(3):331-6. doi: 10.2478/raon-2019-0037.

13. Robertson I, Leung E, Hughes D, Spiers M, Donnelly L, Mackenzie I, et al. Prospective analysis of stoma-related complications. Colorectal Disease 2005; 7(3):279-85. doi: 10.1111/j.1463-1318.2005.00785.x.

14. Keller DS, Khorgami Z, Swendseid B, Khan S, Delaney CP. Identifying causes for high readmission rates after stoma reversal. Surgical Endoscopy 2013; 28(4):1263-8. doi: 10.1007/s00464-013-3320-x.

15. Kye BH, Kim HJ, Kim JG, Cho HM. The nutritional impact of diverting stoma-related complications in elderly rectal cancer patients. Int J Colorectal Dis 2013; 28(10):1393-1400. doi: 10.1007/s00384-013-1699-4. 